\title{
The Use of Ceramics in Total Hip Arthroplasty
}

\author{
D Gamble ${ }^{1}$, PK Jaiswal ${ }^{1 *}$, I Lutz ${ }^{2}$ and KD Johnston ${ }^{3}$ \\ ${ }^{1}$ Department of Orthopaedics, Guys and St Thomas Hospital, UK \\ ${ }^{2}$ Division of Orthopaedics, University Saskatchewan, Saskatoon, Canada \\ ${ }^{3}$ Department of Orthopaedics, Rocky view Hospital, University Calgary, Canada
}

Submission: December 22, 2016; Published: January 06, 2017

*Corresponding author: PK Jaiswal, Department of Orthopaedics, Guys and St Thomas Hospital, $1^{\text {st }}$ floor Bermondsey Wing, Guy's Hospital, UK, Tel: +442071884474; Email: mailto:pkjresearch@gmail.com

\begin{abstract}
Ceramics have excellent mechanical properties and very stable wear characteristics and therefore have been used in many industries including automotives, aeronautics and healthcare. The use of ceramics in total hip arthroplasty has been increasing. This review article we will provide an overview of where we started and how far we have come. We will review the mechanical properties of ceramics, the generations of ceramic implants, and discuss not only the outcomes in pure ceramic on ceramic bearings, but also ceramic on polyethylene bearings and the complications that have developed but also. Finally we will speculate possibilities for future endeavours.
\end{abstract}

Keywords: Alumina; Bearing surfaces; Ceramic; Total hip arthroplasty

\section{Introduction}

Ceramic components were first introduced in the early 1970 's as an alternative bearing surface in an effort to improve wear characteristics and rates of aseptic loosening. The first generation ceramics were made of pure alumina, and were processed from industrial grade materials using high temperature sintering. This produced large grain sizes ( $>5 \mathrm{um}$ ) and relatively impure alumina compared to contemporary ceramics today. Furthermore, fixation of the ace tabular component (either with cement or press-fit) was suboptimal, leading to early failure as well as high fracture rates [1]. Additionally, first generation ceramics were pure zirconia components and batches of zirconia experienced unanticipated roughening and component fractures. The second generation of ceramics added molecules such as calcium and magnesium oxide to decrease the grain size. The third generation of ceramics used a different form of processing called Hipped. The ceramic underwent hot isostatic pressing with the use of pressurized gas. Other changes that were made at the time were optimizing grain size, increasing purity and the use of pre-sterilization loading to assure adequate material properties. An example of this is the BIOLOX® forte. The emergence of BIOLOX® forte femoral heads has substantially reduced the rate of fracture to $0.021 \%$ [2].

The newest (fourth) generation is commonly known as alumina matrix composite material. Its clinical use started in the early 2000's and has been found to have significantly better wear properties in the lab than previous generations [3]. BIOLOX $®$ delta, an example of a fourth-generation ceramic, has even higher grain uniformity and smaller grain size than previous generations. Alumina still makes up a significant portion of the material, but Zirconium oxide crystals have been added in small amounts to help increase toughness. The zirconia particles are stabilized in a tetragonal phase within the alumina. When fissures occur, the zirconium undergoes a phase change, increases volume and absorbs the energy of the fissure. Strontium oxide is also added in low quantities and forms platelets within the alumina composite. These platelets act to deflect subcritical cracks, similar to re-bar in cement, and therefore adds further toughness to the material. Lastly, chromium oxide is added to the composite to help increase the hardness that was lost by the addition of zirconium [3]. Fourth-generation femoral heads are made with more exact sphericity, with a maximal variance of 5 $\mu \mathrm{m}$ and inserts are confirmed to have a maximal variance of 7 $\mu \mathrm{m}$. Final polishing helps to further decrease surface roughness to $2 \mathrm{~nm}$. Proof testing prior to sterilization is performed with a $50 \mathrm{kN}$ force, which is 60 times that of average body weight. [3]

\section{Mechanical Properties}

Ceramics in general have fairly consistent properties across the generations. The surfaces of biomedical ceramics are smooth and have a low coefficient of friction, which equates to lower wear rates in the laboratory. Toughness and strength varies 
with the generations but all of them are highly wet table. The surface of ceramics permit hydrogen bonding which then creates a lubrication film that ultimately decreases friction and can lead to better wear properties. Ceramics are known to be quite hard, and this is measured in their resistance to surface penetration and deformation in three ways. Firstly, scratch hardness, which is measured by the force needed to cut the material. Secondly, indentation hardness, which is measured by the force needed to cause plastic deformation and finally rebound hardness, which is related to elasticity (a diamond is dropped from a set height). Ceramic bearing surfaces are relatively inert, and this is due to their highly crystalline and stable molecular structure. Unlike metals, that have irregular electron orbitals and permit the formation of ions, ceramics have a stable molecular structure that permits significantly less ion information and therefore help ceramics to be nonconductive to both heat and electricity. Ceramics have a lower density compared to metals, which means that at set volumes, ceramics will weigh less. When comparing ceramics within the generations, fourth generation ceramic components have a high stiffness and strength that is nearly double that of previous generations (4-point bending strength $>1000 \mathrm{Mpa}$ ) [3]. Overall toughness has doubled, yet hardness has stayed relatively similar in the newest generation. Surfaced smoothness is increased through final polishing and defined clearance between head and liner allows appropriate lubrication and gliding [4].

\section{Wear Rates}

In 2007, Dr. Banchet and colleagues performed tribological tests in the lab to evaluate ceramic, metal and polyethylene characteristics. Repetitive testing was performed in fixed temperature environments using calf serum. After testing all samples were sputtered with silver coating and examined by scanning electron microscopy. The highest friction coefficient was in zirconia ceramic (0.47), followed by cobalt chrome alloy on ultra high molecular weight polyethylene (UHMWPE) (0.11). The composite ceramic on UHMWPE had roughly half the coefficient of friction of the cobalt chrome alloy $(0.6)$ and the ceramic on ceramic had even less still (0.5). In these settings the ceramic and metal surfaces did not show wear, however the UHMWPE did. In the cobalt chrome on UHMWPE setting, the UHMWPE roughness was over 18 times greater $(\mathrm{nm})$ then it was in the ceramic bearing surface. Their conclusion was that ceramic on ceramic performed the best in the lab because it had low friction and no observable wear [5].

The actual wear rates of specific bearing surfaces can be measured in cubic millimetres per million cycles $(\mathrm{mm} 3 / \mathrm{mc})$ or millimetres per year. Metal on conventional polyethylene has the highest wear rates at $0.137 \mathrm{~mm} / \mathrm{yr}$. This creates significant clinical problems, because polyethylene particles are the right size to be engulfed by macrophages. After phagocytosis of polyethylene particles, macrophages start the inflammatory cascade by secretion of pre-inflammatroy cytokines, with the end result being osteoclastic activation. This leads to osteolysis and eventually aseptic loosening of total hip arthroplasty components. Metal on metal bearing surfaces were developed in an effort to decrease osteolysis and aseptic loosening. These were found to have significantly less wear (roughly $0.005 \mathrm{~mm}$ / $y r$ ), and initially enthusiasm was quite high with young patients being targeted as the most likely to benefit. At the same time, ceramic on ceramic bearings were developed and their wear ranged from 0.001-0.007 mm/yr [6,7].

Although these hard bearing surfaces had excellent wear characteristics, they had other complications associated with them and therefore attention has returned back to polyethylene liners. Polyethylene fails through abrasive wear, adhesive wear, fatigue and third body wear. The most common cause of osteolysis in metal on polyethylene bearings is through adhesive wear. With high friction levels and lower cross-links, adhesive particles were generated which led to osteolysis. In an attempt to decrease wear particles, polyethylene was developed with a higher level of cross-linking. These highly cross-linked versions were found to be more wear resistant (especially to adhesive wear), had smaller debris particle sizes and had lower femoral head penetration rates. Unfortunately, an increase in the wear profile was accompanied by decreased toughness, ductility and tensile strength. Although this was more significant in situations with polyethylene was thinner such as total knee arthroplasty, an overall benefit was achieved in total hip arthroplasty. The rate of wear in metal on highly cross-linked polyethylene was one third that of conventional polyethylene (0.01-0.042 mm/yr). In the same way, ceramic on highly crossed polyethylene wear rates also decreased to a rate of $0.030 \mathrm{~mm} / \mathrm{yr}[6,7]$. Selvarajah et al. [8] showed wear rate of $0.109 \mathrm{~mm} / \mathrm{yr}$ of highly cross linked polyethylene at $5 y \mathrm{rs}$ coupled with a $36 \mathrm{~mm}$ diameter ceramic femoral head in young patients [8]. Although the wear rates for hard on highly cross-linked polyethylene surfaces are higher than those for hard on hard bearing surfaces, highly cross-linked polyethylene bearings do not have the complications that hard on hard bearing surfaces have such as fracture and squeaking.

Despite this, evidence indicates that the ceramic on ceramic bearing couple has no adverse reaction to wear debris at ten to 20 years [4]. Importantly histological examination of longterm retrievals have identified wear debris within individual macrophages in peri-prosthetic tissue, but the limited quantity or relative inertness of the debris does not generate the foreign body granuloma necessary to trigger the osteolytic reaction [4]. This bearing surface therefore has implications for longevity of the prosthesis with additional attributes of low wear rates and adequate bone stock when revision surgery is required [9].

\section{Complications}

\section{Squeaking}

The etiology of squeaking is still not completely understood. Reports in the literature described the rates of ceramic on ceramic bearing squeaking to be anywhere from $0.3 \%$ to $24.6 \%$ [10]. Chevillotte et al. [11] tested third-generation ceramic 


\section{Orthopedics and Rheumatology Open Access Journal}

bearings in the lab and speculated that squeaking arises as result of disruption of fluid lubrication. This disruption can be from lack of fluid, or can be caused by the interposition of particles (third body) between the head and the cup, particularly metal particles [11]. In the same experimentation, they also confirmed that stripe wear, edge wear, micro fractures, and extreme load can accelerate the phenomenon of squeaking however they are not the major cause of squeaking. A meta-analysis performed in 2012 looked at patient factors as well as component types and positions and found only two statistically significant correlations with squeaking, namely increased BMI and the Stryker Accolade stems [12]. A postulated acoustical mechanism was described by Walter et al. 2010 [13].

They suggested that frictional force is created between two hard surfaces when there is a loss of lubrication. This increase in friction translates into a higher vibrational frequency. The vibrational frequency of ceramics is normally outside the acoustic range of humans, however, in total hip replacements there is a dynamic response to the vibration in the surrounding materials. The stem and metal shell produce resonance with frequencies within the human audible range and this is why some stems are associated with squeaking more than others. In the same setting, squeaking is produced by normal cyclical loading, edge loading, third body wear, impingement and lack of lubrication. Squeaking was diminished by higher concentrated serum and thicker lubricant layers. Clinical and radiographic evaluation of patients who have problematic squeaking is warranted. It is important to determine if there are any signs of impingement or component fracture. Clinically, this correlates with limited and painful range of motion. Plain radiographs should be carefully evaluated to analyze component alignment or failures.

A CT scan can be a useful adjunct if unsure. The frequency, persistence and morbidity of the squeaking must be taken into consideration and if the patient is coping with the sound and there is no pain then reassurance and counseling on avoiding squeaking activities is appropriate. If ceramic fracture or gross malposition is found, or if the squeaking is associated with pain or mental anguish then it is reasonable to proceed with revision surgery. Revision due to squeaking has been reported at $0.2 \%$ in a recent meta-analysis by Owen and Russell [14].

\section{Fracture}

Ceramic fracture was much more common with earlier generations with fracture rates reported as high as $13.5 \%$ [15]. The current fracture rate for fourth-generation ceramics estimated by the Ceram Tec company is 1 in 50,000. They state that the fracture rate of femoral head fracture is roughly $0.003 \%$ compared to $0.021 \%$ with pure alumina femoral heads. The fracture rate of liners is reported to have remained stable at around $0.03 \%$. This statement is supported by a review of the literature by Mason et al. [16] Although the mechanical properties of fourth-generation ceramics are much better, when using ceramic bearings careful attention to component positioning, soft tissue tensioning, bearing surface impaction needs to be given [16]. The evidence also suggests that a $36 \mathrm{~mm}$ head seems to be the optimal size in order to prevent impingement without increasing micro separation of large diameters [16].

Diagnosis of ceramic component fractures is sometimes difficult. On physical examination, crepitus within the joint can be suggestive of ceramic fracture. When evaluating plain radiographs, femoral head fractures can be can be suggested by joint asymmetry, component positioning and subtle lucencies. Aspiration of the joint looking for the presence of ceramic fragments greater than five micro millimetres in the synovial fluid is suggestive of liner fracture [17]. If fracture is identified then revision surgery is necessary. Revision can be to a ceramic on ceramic or ceramic on cross-linked polyethylene bearing surfaces.

\section{Stripe wear}

Stripe wear manifests itself as a narrow area of damage of the femoral head and ceramic cup. It is a problem that is unique to ceramic on ceramic bearing surfaces. It has been associated with squeaking and requirement for revision [18] and therefore an important problem to address. The pattern of wear is related to line contact between the head and the edge of the liner [19]. Initial theories were that surgical error was associated with stripe wear with the first two generations of ceramic bearing surface. Series suggested that steep cup angles, use in young patient demographic and revision surgery resulted in aseptic loosening and migration of the cup which led to high stress loading on the femoral head and edge of the liner [20]. However ongoing evidence of stripe wear in 3rd generation ceramics for which improved materials and surgical technique that lead to optimum position of the implants has lead to more complex theories being adopted [21].

Firstly a theory of micro separation when the bearing enters the swing phase leads to edge loading on heel strike was proposed. This was later expanded by walter et al. [19] who reviewed a series of 16 patients that had underwent ceramic revision. Findings of a retroverted location of stripe wear on 9 of the femoral heads meant that edge loading whilst walking was not the only theory accountable for the stripe wear pattern [19]. Therefore they demonstrated that this variation of stripe wear was secondary to loading of the posterior edge as patients moved from flexed to extended position [22]. This posterior edge loading is not unique to ceramic bearing surfaces but the manifestation of stripe wear is. In UHMWPE linings the bearing surface is too soft to cause stripe wear on the ceramic head [23]. Equally, on metal on metal bearing surfaces the polishing material characteristics following wear makes it difficult to identify patterns of wear.

\section{Liner dissociation}

There are reports of liner dissociation in the literature [4], and these situations can prolong surgery or create the need for 


\section{Orthopedics and Rheumatology Open Access Journal}

revision surgery. Titanium shells have both thinner walls and lower stiffness than ceramic liners and if a shell is inserted into dense bone and undergoes deformation, it will be more difficult to seat the ceramic liner appropriately. This can lead to chipping and liner dissociation. Other causes of dissociation may be a failure to impact the liner with sufficient force, and also that ace tabular shell design such as Stryker Trident shells [4].

\section{Limited modularity options}

Due to the manufacturing process for ceramics, there are fewer options for acetabular bearing surfaces compared with polyethylene liners (e.g. elevated rim, increased offset and constrained). Similarly, there are fewer options with respect to size of femoral heads as ceramic skirts are not possible if a larger head/neck is required. Despite this there have been some modern advances. On of these includes the Delta Motion device. This is pre assembled and is aiming to overcome several of the concerns regarding operative assembly of ceramic bearing devices namely chipping on insertion and liner canting. This also allows for a $2 \mathrm{~mm}$ titanium shell with a $3 \mathrm{~mm}$ ceramic lining giving a $5 \mathrm{~mm}$ wall thickness such that a $46 \mathrm{~mm}$ liner can accommodate a $36 \mathrm{~mm}$ diameter ceramic liner. One aspect of the design that has been identified as a weakness is the inability to supplement with screws to achieve stability and the difficulty in obtaining primary stability with a thin titanium shell. However the benefits are that it has allowed for use of larger femoral heads and sizes up to $48 \mathrm{~mm}$ are now available. The theoretical benefits in hip arthroplasty of larger heads are improved range of motion, reduced risk of dislocation and potentially improved proprioception [4].

\section{Outcomes}

The main factors attributed to component failure in total hip arthroplasty are bearing surface wear and particle driven osteolysis. [24,25] Early versions of ceramic on ceramic hip replacements had high rates of failure. This was in part due to component fracture secondary to design flaws, material processing as well as technical errors when implanting ceramic liners. [26-28] Further failure in this era of ceramic was also attributed to aspetic loosening secondary to the method of fixation of the components rather than biological reaction to wear debris [29]. New generation ceramics have addressed these flaws and midterm outcomes from 4 th generation bearing in patients under 65 have been published. Adoude et al. [30] published 133 consecutive ceramic on ceramic hip arthoplasties with 4th generation ceramic bearings in patients under 65yrs old. They found no cases of fracture resulting in a $98.5 \%$ survivorship at a mean of 6yrs [30].

It has been highlighted that fracture of the ceramic bearing surface is a major concern regarding outcome in hip arthroplasty. However, some authors have suggested that the fracture rate is often over exaggerated in the modern literature [22]. A recent paper by Kang et al. [31] reviewed third generation aluminaon-alumina THA at 15 yrs [31]. They found no detectable wear, prosthetic loosening or osteolysis with a survival rate of $98.9 \%$. In addition in their cohort of 90 hips they reported no fracture of the ceramic bearing. This paper provided long term outcomes after previous studies had demonstrated encouraging results in short-midterm follow up [32-37] In their series Lee et al. [38] showed a 10yr survival rate of $99 \%$ using revision as their end point [38].

In young patients ceramic on ceramic bearing outcomes are an area of particular interest. This is because evidence from metal on polyethylene bearings in this demographic has yielded poor results. In patients under 30yrs of age high rates of loosening have been identified with failure rates in the literature reported as high as $45-54 \%$ at $9-15$ years following surgery [39,40]. A study analysing ceramic on ceramic implants in a similar age group showed survivorship averaging $90.3 \%$ at 10yrs with the lowest rates of aseptic loosening amongst bearing surfaces [41].

\section{Revision}

Younger age and higher activity levels are important factors that increase the risk of wear debris and subsequent mechanical failure in total hip arthroplasty. Ceramic on ceramic and metal on metal articulations are bearing s with low wear debris and have therefore become an attractive alternative in patients with high functional demand [42]. A recent meta-analysis reviewed the revision rates between the two hard bearing surfaces. Metal on metal showed higher revision rate than Ceramic on ceramic for any reasons in both studies in cementless hip arthoplasty [38].

Ceramic on metal is a relatively new bearing surface in hip arthroplasy with limited evidence to support its use [43]. Despite this there are perceived benefits with this articulation that would theoretically provide advantages over other hard bearing articulations. These include: potential for larger head sizes, lower metal ion levels, protection against problems associated with implanting ceramic liners and protection from damage and stripe wear to the ceramic head [43]. Recent evidence identified lower than expected survivorship and higher than expected ion levels and thus there use is currently not recommended until further data is available [43].

There are mixed findings in the literature regarding revision rates between ceramic on polyethylene and ceramic on ceramic surfaces. Dongcai et al. [44] reviewed 9 RCTs comparing ceramic on polyethylene and ceramic on ceramic articulations. They found ceramic on ceramic significantly decreased the rates of revision, osteolysis, aseptic loosening and dislocation. They did identify an increased risk of squeaking and implant fracture [44]. A recent meta-analysis [45] looked at short to midterm survivorship among total hip bearing surfaces. They conducted a systematic review of published RCTs after 2000 that looked at ceramic on ceramic, ceramic on highly cross-linked polyethylene or metal on highly cross-linked polyethylene bearings in patients that were 65 years of age or younger. Both direct comparison meta-analysis and network meta-analysis found no difference 


\section{Orthopedics and Rheumatology Open Access Journal}

among the 2599 bearing surfaces in terms of risk of revision. More importantly, all three bearing surfaces performed significantly better than previous metal on standard polyethylene bearing surfaces. Another study has identified no significant difference in survivorship at $10 \mathrm{yrs}$ between ceramic on ceramic and metal on highly cross linked polyethylene bearings. However, the wear rate is significantly lower with the use of ceramics which is likely to have implications at long term follow up [46].

\section{Metal toxicity}

There have been a number of cases of metal toxicity in the literature from revision of a fractured ceramic bearing to a metal on polyethylene bearing surface. It is proposed that residual ceramic debris was trapped within the joint, leading to accelerated cobalt chromium wear and resultant cobalt toxicity. Toxicity to metal ions is often concentration dependent, however some ions are more toxic than others. Cobalt toxicity is the most important to evaluate in the setting of total hip arthroplasty revisions. Cobalt toxicity is a clinical diagnosis, aided by measuring blood cobalt levels. History to evaluate for cobalt toxicity should include looking for symptoms of heart failure or arrhythmias, hypothyroidism, paraesthesia's, auditory and visual deficits, mood and cognitive changes and G.I. symptoms [47].

If patients have malnutrition, it can lead to increased toxicity. Typically a majority of serum cobalt is bound to albumin, however, in poor nutritional states there are less blood proteins and therefore ion levels in the blood will be increased. In patients with renal failure, clearance of cobalt is lower and therefore these patients are at a higher risk for toxicity. Following history and physical examination a workup for cobalt toxicity would include cobalt and chromium ion levels. It is important to test whole blood and evaluate the levels of cobalt in parts per billion. There is no acceptable standard for the actual level, however being above $7 \mathrm{ppb}$ is suggestive of excessive wear in metal-onmetal hip implants [48]. Both high levels and increasing levels are worrisome for adverse local tissue reactions as well as metal toxicity.

The large majority of systemic toxicity cases were associated with cobalt levels greater than $100 \mathrm{ppb}$ [48]. With respect to treatment, the best long-term solution is to remove the offending agent. This means not revising ceramics to metal on poly bearing surfaces, or in the case of metal-on-metal bearings to convert to a standard bearing surface. Chelating agents have been tried in both human and animal cases, however there is no consensus on which chelating agent is best or if chelating agents are even appropriate. Hemodialysis is also unlikely to provide much benefit because, as we discussed earlier, a significant proportion of the cobalt is bound to albumin.

\section{Conclusion}

Total hip arthroplasty operations are projected to continue to increase in frequency in the years to come [49]. Equally the operation is being conducted on an increasingly younger demographic who are more active establishing the need for bearing surfaces that can tolerate a higher functional demand. Despite the excellent long-term results of the "operation of the century" [50] the bearing surface combination that provides optimum results is still a highly contentious and debated issue amongst the orthopaedic community. Given that the biggest cause for failure of hip arthroplasty is aseptic loosening the proven low wear rates in the ceramic based bearing surfaces and high biocompatibility mean that they have the lowest values of aseptic loosening amongst the current options. The fact that wear rates are uniform despite increasing femoral head size allows for the use of larger heads which allow a greater range of movement and protect against risk of dislocation. In addition the advances in ceramic manufacturing in combination with improved surgical technique mean that the perceived disadvantages of fracture, stripe wear and squeaking are decreasing in prevalence. It is clear more evidence of long term outcomes is needed but the current picture supports use of this bearing surface in orthopedics particularly in the younger patient demographic.

\section{References}

1. Beckmann NA, Gotterbarm T, Innmann I, Merle C, Bruckner T, et al (2015) Long-term durability of alumina ceramic head in THA. BMC Musculoskelet Disord 16:249.

2. Sadoghi P, Pawelka W, Liebensteiner MC, Williams A, Leithner A, et al. (2014) The incidence of implant fractures after total hip arthroplasty. Int Orthop 38(1): 39-46.

3. Mason B (2009) Emergence of the alumina matrix composite in total hip arthroplasty. Int Orthop 33(2): 359-363.

4. Jeffers JR, Walter WL (2012) Ceramic-on-ceramic bearings in hip arthroplasty: state of the art and the future. J Bone Joint Surg Br 94: 735-745.

5. Banchet V, Fridrici V, Abry J, Ph Kapsa (2007) 'Wear and friction characterization of materials for hip prosthesis'. Wear. 263(7-12): 1066-1071.

6. Yoshitoshi Higuchi, Hasegawa, Yukiharu, Seki Taisuke, Ishiguro N (2016) Significantly Lower Wear of Ceramic-on-Ceramic Bearings than Metal-on-Highly Cross-Linked Polyethylene Bearings: A 10- to 14-Year Follow-Up Study. J Arthroplasty 31(6): 1246-1250.

7. Sentuerk U, von Roth P, Perka C (2016) Ceramic on ceramic arthroplasty of the hip: new materials confirm appropriate use in young patients. Bone Joint J 98-B(1 Suppl A): 14-17.

8. Selvarajah E, Hooper G, Grabowski K, C Frampton, T B F Woodfield et al. (2015) The rates of wear of X3 highly cross-linked polyethylene at five years when coupled with a $36 \mathrm{~mm}$ diameter ceramic femoral head in young patients. Bone Joint J 97-B: 1470-1474.

9. Cash DJ, Khanduja V (2014) The case for ceramic-on-polyethylene as the preferred bearing for a young adult hip replacement. Hip Int 24(5): 421-427.

10. Levy YD, Munir S, Donohoo S, Walter WL (2015) Review on squeaking hips. World J Orthop 6(10): 812-820.

11. C Chevillotte, R T Trousdale, Q Chen, O Guyen, K N An (2010) “The 2009 frank stinchfield award: 'hip squeaking': a biomechanical study of ceramic-on-ceramic bearing surfaces". Clin Orthop Relat Res 468(2): 345-350. 
12. Stanat SJ, Capozzi JD (2012) Squeaking in third- and fourth-generation ceramic-on-ceramic total hip arthroplasty meta-analysis and systematic review. J Arthroplasty. 27(3): 445-453.

13. Walter WL, Yeung E, Esposito C (2010) A review of squeaking hips. J Am Acad Orthop Surg 18(6): 319-326.

14. Owen DH, Russell NC, Smith PN, Walter WL (2014) An estimation of the incidence of squeaking and revision surgery for squeaking in ceramic-on-ceramic total hip replacement: a meta-analysis and report from the Australian Orthopaedic Association National Joint Registry. Bone Joint J 96-B(2): 181-187.

15. Willmann G (2000) Ceramic femoral head retrieval data. Clin Orthop Relat Res 379: 22-28.

16. Massin P, Lopes R, Masson B, Mainard D, French Hip \& Knee Society (SFHG) (2014) Does Biolox Delta ceramic reduce the rate of component fractures in total hip replacement. Orthop Tramatol Surg Res 100(6): S317-S321.

17. A Toni, F Traina, S Stea, Sudanese A, Visentin M, et al. (2006) "Early diagnosis of ceramic liner fracture: guidelines based on a twelve-year clinical experience". Journal of Bone and Joint Surgery Am 88(4): 5563.

18. Walter WL, Lusty PJ, Watson A, O’Toole G, Tuke MA, et al. (2006) Stripe wear and squeaking in ceramic total hip bearings. Semin Arthroplast 17(3): 190-195.

19. Walter WL, Insley GM, Walter WK, Tuke MA (2004) Edge loading in third generation alumina ceramic-on-ceramic bearings: stripe wear. J Arthroplast 19(4): 402-413.

20. Nevelos JE, Prudhommeaux F, Hamadouche M, Doyle C, Ingham E, et al. (2001) Comparative analysis of two different types of aluminaalumina hip prosthesis retrieved for aseptic loosening. J Bone Joint Surg Br 83(4): 598-603.

21. Nevelos J, Ingham E, Doyle C, Streicher R, Nevelos A, et al. (2000) Microseparation of the centers of alumina-alumina artificial hip joints during simulator testing produces clinically relevant wear rates and patterns. J Arthroplast 15(6): 793-795.

22. Macdonald N, Bankes M (2014) Ceramic on ceramic hip prostheses: a review of past and modern materials. Arch Orthop Trauma Surg 134(9): 1325-1333.

23. Harris WH (2012) Edge loading has a paradoxical effect on wear in metal-on-polyethylene total hip arthroplasties. Clin Orthop Relat Res 470(11): 3077-3082.

24. Dumbleton JH, Manley MT, Edidin AA (2002) A literature review of the association between wear rate and osteolysis in total hip arthroplasty. J Arthroplasty 17(5): 649-661.

25. Harris WH (2001) Wear and periprosthetic osteolysis: the problem. Clin Orthop Relat Res 393: 66-70.

26. Boutin P (200) Total hip arthroplasty using a ceramic prosthesis. Clin Orthop Relat Res 379: 3-11

27. Yoo JJ, Kim YM, Yoon KS, Koo KH, Song WS, et al. (2005) Alumina-onalumina total hip arthroplasty. A five-year minimum follow-up study. J Bone Joint Surg Am 87(3): 530-535.

28. Sedel L, Nizard RS, Kerboull L, Witvoet J (0994) Alumina-alumina hip replacement in patients younger than 50 years old. Clin Orthop Relat Res 298: 175.

29. Jazrawi LM, Bogner E, Della Valle CJ, Chen FS, Pak KI, et al. (1999) Wear rates of ceramic-on-ceramic bearing surfaces in total hip implants: a 12-year follow-up study. J Arthroplasty 14: 781-787.

30. Aoude A A, Antoniou J, Epure L M, Huk OL, Zukor DJ, et al. (2015) Midterm Outcomes of the Recently FDA Approved Ceramic on Ceramic
Bearing in Total Hip Arthroplasty Patients Under 65 Years of Age. J Arthroplasty 30(8): 1388-1392.

31. Kang BJ, Ha YC, Ham DW, Hwang SC, Lee YK, et al. (2015) Thirdgeneration alumina-on-alumina total hip arthroplasty: 14 to 16-year follow-up study. J Arthroplast 30(3): 411-415.

32. Kim YH, Park JW, Kim JS (2012) Cementless metaphyseal fitting anatomic total hip arthroplasty with a ceramic-on-ceramic bearing in patients thirty years of age or younger. J Bone Joint Surg Am 94(17): 1570-1575.

33. Lee YK, Ha YC, Yoo JJ, Koo KH, Yoon KS, et al. (2010) Alumina-onalumina total hip arthroplasty: a concise follow-up, at a minimum of ten years, of a previous report. J Bone Joint Surg Am 92(8): 1715-1719.

34. Yeung E, Bott PT, Chana R, Jackson MP, Holloway I, et al. (2012) Midterm results of third-generation alumina-onalumina ceramic bearings in cementless total hip arthroplasty: a ten-year minimum follow-up. J Bone Joint Surg Am 94(2): 138-144.

35. Chana R, Facek M, Tilley S, Walter WK, Zicat B, et al. (2013) Ceramicon-ceramic bearings in young patients: outcomes and activity levels at minimum ten-year follow-up. Bone Joint J 95- B(12): 1603-1609.

36. D Antonio JA, Capello WN, Naughton M (2012) Ceramic bearings for total hip arthroplasty have high survivorship at 10 years. Clin Orthop Relat Res 470(2): 373-381.

37. Hamilton W G, McAuley J P, Blumenfeld T J, Lesko JP, Himden SE, et al. (2015) Midterm results of Delta ceramic-on-ceramic total hip arthroplasty. J Arthroplasty 30(9 Suppl): 110-115.

38. Lee YK, Yoon BH, Choi YS, Jo WL, Ha YC, et al. (2016) Metal on metal or ceramic on ceramic for cementless total hip arthroplasty: A metaanalysis. J Arthoplasty 31(11): 2637-2645.

39. Dorr LD, Luckett M, Conaty JP (1990) Total hip arthroplasties in patients younger than 45 years: a nine to ten year follow-up study. Clin Orthop Relat res 260: 215-219.

40. Torchia ME, Klassen RA, Bianco AJ (1996) Total hip arthroplasty with cement in patients less than twenty years old: long-term results. J Bone Joint Surg Am 78(7): 995-1003.

41. Hannouche D, Devriese F, Delambre J, Zadegan F, Tourabaly I, et al. (2016) Ceramic-on-ceramic THA implants in younger patients than 20 years. Clin Orthop Relat Res 474(2): 520-527.

42. Shetty V, Shitole B, Shetty G, Thakur H, Bhandari M (2011) Optimal bearing surfaces for total hip replacement in the young patient: a meta-analysis. Int Orthop 35: 1281-1287.

43. Hill J C, Diamond O J, O Brien S, Boldt JG, Stevenson M, et al. (2015) Early surveillance of ceramic-on-metal total hip arthroplasty. Bone Joint J 97-B(3): 300-305.

44. Dongcai H, Yang X, Tan Y, Alaidaros M, Chen L (2015) Ceramic-onCeramic Versus Ceramic-on-Polyethylene Bearing Surfaces in Total Hip Arthroplasty: A meta-analysis of randomized controlled trials. Orthopaedics 38(4): e331-e338.

45. Wyles CC, Jimenez-Almonte JH, Murad MH, Norambuena-Morales GA, Cabanela ME, et al. (2015) There are no differences in short to midterm survivorship among total hip bearing surface options: a network meta-analysis. Clin Orthop Relat Res 473(6): 2013-2041.

46. Higuchi Y, Hasegawa Y, Taisuke S, Komatsu D, Ishiguro N, et al. (2016) Significantly Lower Wear of Ceramic-on-Ceramic Bearings Than Metal-on-Highly Cross-Linked Polyethylene Bearings: A 10- to 14-Year Follow-Up Study. J Arthroplasty 31(6): 1246-1250.

47. Cheung AC, Banerjee S, Cherian JJ, Wong F, Butany J, et al. (2016) Systemic cobalt toxicity from total hip arthroplasties: review of a rare condition Part 1 - history, mechanism, measurements, and pathophysiology. Bone Joint J 98-B(1): 6-13. 
48. MacDonald SJ (2004) Can a safe level for metal ions in patients with metal-on-metal total hip arthroplasties be determined?. J Arthroplasty 19(8 Suppl 3): 71-77.

49. Kurtz S, Ong K, Lau E, Mowat F, Halpern M (2007) Projections of primary and revision hip and knee arthroplasty in the United States from 2005 to 2030. J Bone Joint Surg Am 89(4): 780-785.

50. Learmonth ID, Young C, Rorabeck C (2007) The operation of the century: total hip replacement. Lancet 370 (9597): 1508-1519.

\begin{tabular}{l} 
Your next submission with JuniperPublishers \\
will reach you the below assets \\
- Quality Editorial service \\
- Swift Peer Review \\
- Reprints availability \\
- E-prints Service \\
- Manuscript Podcast for convenient understanding \\
- Global attainment for your research \\
- Manuscript accessibility in different formats \\
( Pdf, E-pub, Full Text, A udio) \\
- Unceasing customer service \\
Track the below URL for one-step submission \\
https://juniperpublishers.com/online-submission.php \\
\hline
\end{tabular}

